\title{
Research on the Development Status and Strategy on Sustainable Fashion of Fast Fashion Brands
}

\author{
Lei YAO ${ }^{1}$ and Jing ZHANG \\ ${ }^{1}$ Beijing Institute of Fashion Technology, Beijing, 100029, China \\ E-mail: sxyyl@bift.edu.cn
}

Keywords: Sustainable fashion, fast fashion, sustainable development

\begin{abstract}
With the acceleration of people's pace of life and the rapid development of economy, fast fashion brands swiftly attracts people's attention with low price, multiple styles and small quantity, fully satisfying consumer demands. But as the increasing deterioration of mankind's living environment, especially with fashion industry being the globally second largest industry polluting the environment, more attention and emphasis shall be laid on the sustainable development of fashion industry, which is an inevitable choice for fashion industry development under the development and survival crisis of human society. As the sustainable development of economy is an important part of sustainable development, this article, based on the development of fast fashion brands in clothing industry, adopts case study method to compare and analyze the characteristics of further development of fast fashion brands under the general background of sustainable development, putting forward relevant strategies and measures for the sustainable development of fast fashion brands to further facilitate the sustainable development of fashion brands, which can advance the long-term development of fast fashion brands, boost fast fashion brands and develop fast fashion economy in a healthier and more benign way.
\end{abstract}

\section{Introduction}

Fashion industry has always been accused for the negative effects it brought in sustainable development since it, as the globally second largest industry polluting the environment, has constantly brought tremendous negative effects on global resources and ecological environment. With the acceleration of people's pace of life, fast fashion brands show up in people's eyes and quickly attract their attention with its quick response to fashion, low price and abundant styles while it brings more realistic problem in speeding up the circulation of clothing industry: exhausting natural resources in advance and expediting the disruption of ecological environment. As wider attention of the globe has been placed on these issues, the concept of "sustainable fashion" is raised and thought highly of more frequently. By conducting comparison and analysis on the characteristics of sustainable fashion design of fast fashion brands, the article put forwards corresponding feasible suggestions that are closer to theories and of great realistic significance of the revolution and sustainable development of fast fashion industry.

\section{The Development Status of Sustainable Fashion of Fast Fashion Brands}

In recent years, more and more importance and focus have been placed on the behaviors of fast fashion brands of seriously wasting resources and destroying the environment. Nevertheless, recent years also witnesses the successive efforts made by fast fashion industry in sustainable development to jointly shoulder its responsibility for global environmental issues. The sustainable development status of fast fashion brands will be discussed from the perspective of the relevant policies made for brand sustainable development by three most representative fast fashion brands ZARA, H\&M and Uniqlo, which have been selected for case study. 


\section{The Sustainable Development Status of H\&M}

As one of top fast fashion brand around the world and a member of Global Fashion Agenda (GFA) which dedicates to sustainability and recycle production, H\&M has been committing to the development premise of sustainability and become the most active company promoting sustainable development in fast fashion field in the past few years.

From the 2017 Sustainability Report released by H\&M group, we can see the endeavors it made and social responsibilities it undertook for sustainable development.

Three key strategic and magnificent ambitions of H\&M group about sustainable development have been pointed out in the 2017 Sustainability Report, including 100\% leading the change of fashion industry, 100\% circular \& renewable and 100\% fair \& equal.

\section{Garment Collecting}

In 2017, H\&M group collected 17,771 tons of unwanted textiles in total all over the world via garment collecting scheme, including 482 tons in Chinese market and reused and recycled them by scientific means. The garment collecting scheme at all H\&M stores around the world began in 2013, since when the group has collected more than 61,000 tons of unwanted garment via the activity. These unwanted garments will be reused by scientific means to achieve recycling, decrease the proportion of textiles buried and burned to reduce the damage of disposing unwanted textiles to the environment and ecology.

\section{Toxic-free Garment Production}

Garment production industry is the globally second largest industry polluting the environment, and in order to reduce the pollution and further promote the goal of sustainable development, the group formulates relevant policies and rules on the use of chemical products during the entire garment production to drive the fashion industry towards toxic-free orientation and reduce the damage and waste of water in garment production, weaken the negative effects of garment production on ecology and boost ecological development and global sustainable development.

\section{Sustainable Materials}

The goal set on materials by H\&M group is to use $100 \%$ sustainable sources for the cotton used in the whole series of products by the group as of 2020. As of now, H\&M group has become the biggest buyer of Better Cotton in the world and has been named the globally second largest user of recycled cotton and cotton free of chemical pesticide during production. Each year, H\&M group will increase the use proportion of sustainably-sourced material to achieve its key strategic ambition of the group by 2030 - to use $100 \%$ recycled or other sustainably-sourced materials for the garment produced by the group and so far, the proportion of recycled and other sustainably-sourced materials adopted by H\&M group has taken up 35\% of all materials used.

\section{Introducing Talents}

In order to realize the three key strategic and magnificent ambitions of sustainable development, H\&M group will further promote its unwanted garment collecting scheme via various means and harbor an active attitude to cooperate with institutions of higher education of garment on sustainable development, encourage the development of sustainable fashion and absorb talents in sustainable fashion. In 2018, H\&M group will collaborate with Shanghai International College of Fashion and Innovation, Donghua University to jointly advance sustainable fashion and actively foster talents in sustainable development.

\section{The Sustainable Development Status of Uniqlo}

"Changing clothes. Changing conventional wisdom. Change the world." This is the corporate statement of the Fast Retailing they established, which means to change the society with the stimulation of their commercial activities and products, embodying the belief of Uniqlo: a sustainable world is the most important commercial goal of Uniqlo. 
In order to realize the goal of sustainable development, Uniqlo made a new sustainable statement in 2017 and divided key issues into four priorities: supply chain, product, store and community and employee.

\section{Store and Community}

In terms of store, Uniqlo group has increased the working efficiency of energies, manage and collect trashes, use more sustainable storage materials in stores and so on and in terms of community, the group works with communities to facilitate stable and sustainable growth and attracts customers and employees attending community outward activities.

\section{Supply Chain}

In terms of supply chain, it shows respect to human rights, reduces waste and environmental impact. It establishes stable foundation for business growth and guarantees traceability by keeping in close contact with business partners and publicizes the factory list of Uniqlo and its core partners. Through Ariake project, Uniqlo is reshaping fast retail business, and in consideration of sustainability, the company will reexamine all procedures, not just production and logistics so that they can see their business operation before making decisions and become more and more sustainable.

\section{Product}

In terms of product, it will take sustainable material as a priority when purchasing raw materials to create more sustainable products and provide products conducive to social environment. Good clothes mean simple and quality ones that are endurable. It is a kind of clothes that bring people coziness, protection and happiness and produced in a naturally harmonious way that will not create over-burden negative effects to the environment. Uniqlo commits to unremittingly dedicate to creating a better and sustainable society.

\section{Employee}

In terms of employee, since the spring in 2017, they have asked their 110,000 employees all over the world, including those in retail stores to participate in online courses or other sustainable development training courses in eight languages. Over $70 \%$ employees completed the training by the end of August, 2017, which not only conducted sustainable education to labor force from commercial perspective but also worked on how to increase the engagement of employees in sustainable development. "Changing clothes. Changing conventional wisdom. Change the world." This is the corporate statement of the Fast Retailing they established, which means to change the society with the stimulation of their commercial activities and products.

\section{The Sustainable Development Status of Zara}

In full realization that the priority of a company is to protect the environment and human rights, Zara group aims to produce beautiful and lofty products that are not only correct for customers, but also to the staffs of the enterprise, the community and to the environmental rights and create a fashion suitable for wearing. The group has formulated the highest sustainable standard and strictest behavior standard, which has been deemed leader in their work by many enterprises in the industry.

\section{Series of Clothes}

It can be seen from the official website of Zara that it has launched JoinLife project for sustainable development, the series of which mainly adopt environmentally friendly materials. The series claim to use sustainable materials including BCI cotton and TENCEL ${ }^{\circledR}$ lyocell during manufacturing of the series of cloths. TENCEL ${ }^{\circledR}$ lyocell, a kind of fiber from tree farms that are sustainable themselves and is produced in a closed-loop process, with 100\% water used for production and 95\% chemicals reusable. 


\section{Garment Collecting}

In order to carry out unwanted garment collecting scheme, Zara has set up more than 300 collecting stations in its stores in Portuguesa, Holland, Denmark and Sweden and started its unwanted garment collecting in China in 2016. Zara will strive to set up collecting stations to collect unwanted garments in its stores all over the world in the next several years.

\section{Sustainable Resources}

Zara also claims that $84 \%$ energy consumed by website operation is from recycled, environmentally friendly and sustainable energy. In addition, the majority of Zara stores have reached high-efficiency ecological standard and the group is committed to using $100 \%$ recycled energy in work place and servers for office use by 2018 and reducing 20\% energy consumption in overall consumption by 2020.

The efforts made by fast fashion brands in regard to sustainable development mainly focus on the use of sustainable materials and unwanted garment collecting activities, with some brands making corresponding efforts in fostering employees' sustainable development consciousness and facilitating enterprises' sustainable development by scientific and technological means. In recent years, fast fashion brands have gradually come to realize the importance of sustainable development, which not only ensures the long-term development of enterprises, but is a social responsibility granted by all mankind, and each garment enterprise shall make their contributions in the sustainable development of global ecological environment.

\section{Impediments to Sustainable Development of Fast Fashion Brands}

\section{Impediments Caused by "Fastness"}

The most distinctive feature of fast fashion brands is that they are able to quickly respond to the latest runway fashion information. In addition, the enterprises can quickly manufacture clothing products with corresponding fashion elements, and then put them on the market rapidly through their powerful logistics systems to effectively meet modern people's needs to purchase stylish garments.

\section{Contradiction between "Quantity” and Fastness}

"Fastness", the most direct and most distinctive feature of fast fashion brands, is embodied in their quick response, strong industry chains and outstanding approaches to marketing, which means shortening of the style change cycle and continuous diversification of styles. Despite the fact that fast fashion brands adopt the hunger marketing strategy and manufacture each style in small quantities, due to shortening of the change cycle and continuous diversification of styles, the total quantity of clothing is very high. Furthermore, coupled with hunger marketing, the novel styles will attract customers to purchase more clothing, which in turn motivates the enterprises to further increase the production quantity. All these factors have resulted in waste of a large quantity of clothing and further damage to the ecological environment.

\section{Contradiction between "Materials" and Fastness}

In recent years, fast fashion brands have realized the importance of sustainable development, thus successively beginning to adopt various measures to respond to the trend of sustainable development, among which the main measure is using environmentally friendly and sustainable raw materials. However, the production and processing cycles of such raw materials are longer than the average production cycles of ordinary raw materials for manufacturing clothing, which means a longer clothing production cycle. A slow-down in the first link in the production chain means a slow-down in the whole production chain, which seriously deviates from the requirement for fast fashion to quickly respond to the market. 
Both issues mentioned above involve the contradictions between sustainable development and "fastness" of fast fashion. Fastness is the most distinctive feature of fast fashion brands. If not "fast", fast fashion cannot be so called. Therefore, in this respect, fast fashion and sustainable fashion are contradictory, and how to find a balance between them should be an urgent problem which fast fashion brands need to solve.

\section{Impediments Caused by "Price"}

The clothing offered by fast fashion brands are "affordable fashion" for ordinary consumers. On the strength of low prices, fast fashion brands quickly catch the attention of consumers, quickly stimulate consumers to buy and attract consumers to buy. This is also one of the key major factors contributing to fast fashion brands' ability to quickly occupy the market, and also one of the main features of fast fashion brands.

\section{Contradiction between "Materials" and Price}

In recent years, for long-term development, fast fashion brands have developed a series of sustainable development regulations, including using renewable and sustainable raw materials for manufacturing clothing, such as organic cotton. Such somewhat hi-tech raw materials increase the total cost of manufacturing clothing, which means a violation of the "low price" feature of fast fashion.

\section{Contradiction between “Technology" and Price}

To achieve sustainable development, the enterprises have all become aware of the fact that this industry needs to be supported with innovation. Enterprises need to make efforts in terms of applying production technologies and new materials, bringing in talents, etc., to bring in science and technology so as to create clothing products more in line with the sustainable development requirements. All of these efforts require capital support, which means higher clothing costs in the whole process and results in a violation of the "low price" feature of fast fashion.

"Low price" is an important way by which fast fashion attracts consumers and its essential feature. Nevertheless, the efforts made by the brands in terms of raw materials, technology, etc. for sustainable development have in turn resulted in higher clothing production costs, which constitutes a contradiction between "low price" and sustainable development. How to strike a balance between "low price" and higher costs resulting from "sustainable development" is another problem which should be solved by fast fashion brands.

\section{Strategic Measures Taken by Fast Fashion Brands for Sustainable Fashion Development}

\section{Active Assumption of Social Responsibilities by the Enterprises}

The clothing industry is the "second biggest" pollution-causing industry in the world. Today, as sustainable development is increasingly valued, there is a stronger need for the enterprises to assume their responsibility for environmental protection and actively advocate sustainable development. As a unique fashion production mode emerging in the 80s, in the whole clothing industry, compared with other types of clothing production enterprises, fast fashion clothing production has a more serious adverse impact on the ecological environment. Therefore, there is a greater need for fast fashion enterprises in the 21st century to enhance the awareness of environmental protection by them, take a long-term perspective to view the problem of sustainable development and make efforts to maintain their long-term vitality. Those enterprises shall actively lay down relevant rules and regulations, actively respond to the urgent need for the entire mankind to protect the environment and recycle resources, endeavor to assume their social responsibilities and reduce the adverse impact caused by production activities of clothing enterprises to the environment. 


\section{Use of Sustainable Materials}

Sustainable fashion, also called eco fashion, complies with the sustainable development requirements in its nature, aims to create a system which can be supported in terms of social responsibility and responsibility for the environment, and is composed of three aspects: respect for labor force, use of renewable and sustainable energy and reduction of environment pollution in the clothing production process, of which the selection of materials is the most direct one. When general raw materials for manufacturing clothing are converted to or become usable textiles, a large quantity of hazardous substances will be discharged into the ecological environment, which seriously and adversely affects the ecology. Whether the clothing materials conform to the sustainable development requires should be mainly judged based on the following three aspects: the quantity of greenhouse gases discharged, the quantity of water resources polluted and the quantity of hazardous chemical substances used. People tend to think that natural fiber, cotton, hemp, etc. are environmentally friendly, natural and pollution-free green materials, but this is only true when they are raw materials. When they are converted from raw materials to textiles, a high quantity of substances harmful to the environment come into being and damage the environment. Thus, utilizing science and technology to innovate and use materials and produce new-type materials causing little harm to the environment is a key task for solving relevant problems.

\section{Enhancement of the Enterprises' Reputation in Terms of Sustainable Development}

Sustainable development is a continuous process. While endeavoring to assume their social responsibilities, enterprises will pay a corresponding price, as most directly reflected by the increase in price. Due to development in terms of raw materials, workforce, etc., the clothing production cost will definitely rise, which will result in an increase in the final price and affect the competitiveness of the enterprises' brands. Therefore, the enterprises need perseverance and courage when sticking to sustainable development. At present, the fast fashion brands are all enthusiastically transforming themselves, and endeavoring to make corresponding changes in terms of sustainable development, but the key is how long they can honor such commitment. When some brands stick to sustainable development, various problems are encountered and many problems are exposed, which impair their credibility among the public in terms of their commitments regarding sustainable development. Therefore, the enterprises should be more transparent and self-disciplined and harness reasonable operational strategies in the whole process of sustainable development. Driven by sustainable development, the enterprises can achieve greater development and maintain their reputation.

\section{Advocating and Improvement of the Sustainable Development Awareness among the General Public}

While assuming their social responsibilities, enterprises should advocate the philosophy of sustainable development, and use their influence to actively improve the sustainable development awareness among the general public. The major fast fashion brands are all actively advocating the "used clothing recycling" activity, advertising used clothing recycling through their stores or the Internet, using better ways to re-create and re-use textiles, which have reduced damage to the environment, boosted the general public's participation in sustainable development and stimulated the general public's passion for sustainable development. Thus, fast fashion enterprises should, while guaranteeing that their products conform to the sustainable development requirements, actively use their influence to actively communicate to the public the message of sustainable development by holding relevant environmental protection activities, enterprises' publicity efforts, etc., so as to enhance the sustainable development awareness.

\section{Outlook for the Future}

Currently, fast fashion has been accepted by most people and has also been criticized by a lot of people. Sustainable development is a topic shared by the entire mankind, and fast fashion brands should actively adopt corresponding strategies and approaches in the trend of sustainable 
development, and take a long-term perspective to view the problems. Although fast fashion itself contradicts with sustainable development in many respects, how to strike a balance between them remains a problem which the fast fashion enterprises need to reflect on and solve. In the age of rapid change, the ecological environment is the cornerstone of mankind development, thus fast fashion enterprises should actively assume their social responsibilities, endeavor to reduce the adverse impact caused by clothing production to the environment and accomplish greater development of fast fashion, a special class in the clothing industry.

\section{Acknowledgement}

(1)The key project of social science program for Beijing Municipal Education Commission 2016(SZ201610011208)

(2)Beijing Excellent Talents Cultivating Funding Projects "Research on the optimization path of Beijing garment industry structure under the coordinated development of Beijing Tianjin Hebei” (Fund code: TSJH201510012002)

\section{References}

[1] XIANG Kaiying. Self-redemption of Fashion [J]. ZHUANGSHI, 2011, 5(31): 104-105.

[2] TIAN Hewei. Research on Sustainable Development of Terminal Vitality about Fast Fashion Brand [J]. Progress in Textile Science \& Technology, 2014, 2:90-92.

[3] YANG Xiao. Research on Sustainable Design in Stylish Clothing Marketing Activities [J]. Contemporary Economics, 2016, 4 (2): 104-105.

[4] YAN Ke. Research on Bags Design Based on Sustainable Concept of Design (D) Shanghai: Donghua University, 2017.

[5] WANG Zhihai. On the Path-selection of Sustainable Economic Development in the Ethnic Minority Areas (D) Xinjiang: Xinjiang University, 2008.

[6] WEI Xiaohong. Study on the Biological Capacity under the View of the Sustainable Development (D) Lanzhou: Lanzhou University, 2010. 